the analysis. This remains a difficulty with the Andersen et al. study.

The authors have attempted to address the issue of $\mathrm{CP}$ alone as an outcome. When it comes to consideration of the impact of mode of delivery, CP alone is an inadequate endpoint since the risk to the fetus is of death or damage. Not only is death a crucial endpoint, but it is very possible that some of those who died might have gone on to develop CP should they have survived. The picture of outcomes is, therefore, incomplete and might lead to false assumptions about the usefulness or otherwise of Caesarean section in preventing $\mathrm{CP}$ among singletons presenting by the breech. Birth complications in breech presentation, e.g. cord prolapse or a trapped head, have severe consequences, including perinatal death, and need to be carefully considered along with CP in assessing the safety of a proposed mode of delivery. Consideration of $\mathrm{CP}$ alone may lead to a false impression of the safety of one mode over another.

Following the Term Breech Trial very few vaginal breech deliveries are undertaken in developed countries. Between 1996 and 2005 the rate of vaginal delivery of breech presenting infants halved from over 20 to only $10 \%,{ }^{6}$ most of whom were probably second twins. Deskilling of the obstetric workforce is a growing problem. A proportion of singletons who present by the breech will still either arrive at hospital too late to receive a Caesarean section or have mothers who choose not to have one. It could be argued that, soon, breech delivery will be beyond the experience of most obstetricians and midwives.

\section{REFERENCES}

1. Hannah ME, Hannah WJ, Hewson SA, Hodnett ED, Saigal S, Willan AR, for the Term Breech Trial Collaborative Group. Planned cesarean section versus planned vaginal birth for breech presentation at term: A randomized multicenter trial. Lancet 2000; 356: 1375-83.

2. Andersen G, Irgens L, Skraens J, Salvesen $\mathrm{K}$, Meberg A, Torstein V. Is breech presen- tation a risk factor for cerebral palsy? A 5. Blair E, Al Asedy F, Badawi N, Bower C. Is Norwegian birth cohort study. Dev Med Child Neurol 2009; 51: 860-5.

3. Nelson K, Ellenberg JH. Antecedents of cerebral palsy. N Eng 7 Med 1986; 315: 816.

4. Felix JF, Badawi N, Kurinczuk JJ, Bower C, Keogh JM, Pemberton PJ. Birth defects in children with newborn encephalopathy. Dev Med Child Neurol 2000; 42: 803-8. cerebral palsy associated with birth defects other than cerebral defects? Dev Med Child Neurol 2007; 49: 252-58.

6. Laws PJ, Abeywardana S, Walker J, Sullivan EA. Australia's Mothers and Babies 2005. Perinatal Statistics Series no. 20. Cat. No. PER 40. 2007. Sydney AIHW National Perinatal Statistics Unit. http://www.npsu. unsw.edu.au/NPSUweb.nsf/page/ps20.

\title{
Making a difference
}

\section{EDWARD HURVITZ}

University of Michigan, Physical Medicine and Rehabilitation, Oak Park, MI, USA. See related article ${ }^{3}$

For many years, interventions for children with cerebral palsy (CP) focused on neurorehabilitation and biomechanics. Several methodologies were developed that were based on theory, widely practiced, but not studied in any rigorous fashion. Many practitioners questioned the efficacy of these interventions and wondered if there were long-term, positive effects for those who received them.

The past several years have seen a shift toward evidencebased methods of intervention (e.g. constraint therapy), but the long-term effects of these methods are still under investigation. Perhaps the greatest innovation in CP care over the past 20 years has been that children (and adults) with CP would benefit from exercise and increased physical activity. Led by some of the classic work on strengthen- ing by Diane Damiano and colleagues, and defined by her review on activity as a form of therapy, ${ }^{1}$ exercise and activity have become foci of research and staples of therapy throughout the $\mathrm{CP}$ world.

Children, adolescents, and adults with $\mathrm{CP}$ are less fit than their able-bodied counterparts. There are deficits in strength, flexibility, aerobic capacity, bone density, and levels of activity. While children who are at Gross Motor Function Classification System (GMFCS) levels III to V generally have low percentages of body fat, it appears that ambulatory children (GMFCS I-II) may be caught up in the same obesity epidemic affecting their able-bodied peers. ${ }^{2}$ How does this poor level of fitness affect function in childhood and later in adulthood? We know that adults with CP tend to lose gross motor skills with age; how much of that is attributable to decreased strength, flexibility, and aerobic capacity? How much of the 'premature 
aging' that we hear about in adults with $\mathrm{CP}$ is related to fitness? Do the interventions we perform on children, such as surgeries and injections, help or hinder fitness as they grow up and then age?

There are many things yet to learn about exercise and fitness in CP. In this issue, Olaf Verschuren and colleagues $^{3}$ try to answer one of the important questions: how do deficits in fitness translate into deficits in function? This research team has developed and validated several tests of fitness that require minimal equipment and can be done in an office or school setting with simple training - a tremendous contribution on its own. In this study, they examine several aspects of fitness in children at GMFCS levels I to II and compare them with gross motor function measured via two domains of the Gross Motor Function Measure. They conclude that anaerobic fitness, agility, and strength measured through functional tests had the greatest impact on function. The next step, as they note, is to see if interventions aimed directly at these factors will lead to functional changes.

The authors note that body composition did not predict function. However, they used body mass index (BMI) as their measure. BMI is simple to perform and calculate, and gives an indication of body composition that is easy to follow in clinic. But there are problems with its use in $\mathrm{CP}$ related to differences in fat distribution and muscle mass, and a better measure of body fat percentage may tell us more about the relation to function. Aerobic capacity was also not a predictor.
However, as the authors state, aerobic exercise should be an important part of every exercise program. Even if muscle power and anaerobic capacity are more important for daily activities and functional mobility, aerobic exercise provides long-term cardiovascular benefits and overall increased activity, possibly playing a role in the level of societal participation.

An important question, which is certainly not limited to individuals with $\mathrm{CP}$, is how do we make fitness programs designed to improve health and function, and to instill in children in particular a life-long pattern of healthy physical activity? This is especially true in individuals with disabilities such as $\mathrm{CP}$, where many barriers exist to interfere with fitness attainment. ${ }^{4}$ In a nation that is seeking to reform its health-care system, and to put an emphasis on health promotion and prevention instead of high-tech, high priced advance care, this question crosses the spectrum of the healthy, the ill, and the disabled.

The move toward physical fitness in CP care and research has been a wonderful development. First, exercise and activity make individuals with $\mathrm{CP}$ a part of their community, rather than being someone with 'special needs'. After all, we all need to exercise. In addition, after years of wondering about everything we caregivers do, from Bobath to botulinum toxin, we now can speak to our patients about an intervention that we know will help, will probably have long-term benefits into adulthood, and is based on a growing body of evidence. We know we can make a difference.

\section{REFERENCES}

1. Damiano DL. Activity, activity, activity: rethinking our physical therapy approach to cerebral palsy. Phys Ther 2006; 86: 1534 40.

2. Hurvitz EA, Green LB, Hornyak JE, Khurana S, Koch LG. Body mass index measures in children with cerebral palsy related to gross motor function classification. A clinicbased study. Am 7 Phys Med Rehabil 2008; 87: 395-403.

3. Verschuren O, Ketelaar M, Gorter JW, Helders PJ, Taken T. Relation between physical fitness and gross motor capacity in children and adolescents with cerebral palsy. Dev Med Child Neurol 2009; 51: 86671.

4. Rimmer JH. Physical fitness levels of persons with cerebral palsy. Dev Med Child Neurol 2001; 43: 208-12.

\section{Socio-economic achievements of individuals born very preterm at the age of 27 to 29 years}

\section{SAROJ SAIGAL ${ }^{1}$ | DAVID STREINER ${ }^{2}$ \\ 1 Department of Pediatrics, McMaster University, Hamilton, Ontario, Canada. 2 Department of Psychiatry, University of Toronto, Toronto, Ontario, Canada. See related article ${ }^{5}$}

Follow-up studies on outcomes of preterm infants have received increasing attention owing to the remarkable improvements in the survival of very preterm (VPT) infants. These studies have shown that children born preterm have high prevalences of neurodevelopmental disabilities, behavioural and emotional difficulties, higher rates of dysfunction in cognition and executive functioning, poorer academic achievement, grade failure, and increased 